\title{
PENGARUH LATIHAN DAN PEMULIHAN TERHADAP PENINGKATAN VO2 MAX
}

\author{
Marta Dinata $^{1}$, Surisman ${ }^{2}$ \\ ${ }^{1,2}$ Program Studi Pendidikan Jasmani dan Kesehatan \\ Fakultas Keguruan dan Ilmu Pendidikan Universitas Lampung \\ Jalan Sumantri Brojonegoro No.1 Bandar Lampung 35145 \\ 1e-mail: dr.martadinata@yahoo.co.id
}

\begin{abstract}
Abstrak
Penelitian ini bertujuan untuk mengetahui perbedaan antara metode latihan dan pemulihan terhadap peningkatan VO2 Max. Lokasi penelitian ini di Kota Bandar Lampung. Penelitian ini menggunakan metode eksperimen. Pengambilan sampel menggunakan teknik random sampling.Teknik analisis data menggunakan ANAVA 2 arah dan dilanjutkan dengan uji Tukey. Hasil penelitian adalah: (1) Secara keseluruhan metode latihan denyut nadi tinggi lebih baik dari pada latihan denyut nadi rendah, (2) Pemain yang memakai metode pemulihan aktif metode latihan denyut nadi tinggi lebih baik dari latihan denyut nadi rendah, (3) Bagi pemain yang memakai metode pemulihan pasif latihan denyut nadi rendah lebih baik dari latihan denyut nadi tinggi, (4) Terdapat interaksi antara metode latihan dan metode pemulihan .
\end{abstract}

Kata Kunci: metode latihan, latihan denyut nadi tinggi, latihan denyut nadi rendah

\begin{abstract}
This study aims to determine the difference between exercise and recovery methods to increase VO2 Max. The location of this research is in Bandar Lampung City. This research uses experimental method. Sampling using random sampling techniques. The data analysis technique used 2 way ANOVA and continued with Tukey test. The results of the study were: (1) Overall method of high pulse exercise is better than low pulse exercise, (2.) Players using active recovery methods of high pulse exercise methods are better than low pulse exercise, (3.) For players using passive recovery methods low pulse exercise is better than high-pulse exercise, (4.) There is an interaction between exercise methods and recovery methods.
\end{abstract}

Keywords: exercise method, high pulse exercise, low pulse exercise

\section{PENDAHULUAN}

Sesuai dengan perkembangan ilmu pengetahuan di cabang olahraga, maka latihan fisik lebih diutamakan sebagai pondasi pokok dalam aktivitas misalkan bermain sepak bola. Pada dasarnya kualitas hasil latihan akan terlihat pada bentuk dan fungsi yang diinginkan dalam latihan. Dalam pertandingan sepak bola yang 
waktunya 2 x 45 menit dibutuhkan suatu kemampuan fisik yang kuat untuk bermain selama 90 menit. Dalam latihan selain mempergunakan latihan aerob dan anaerob, diberikan juga latihan pemulihan aktif dan pasif.

Pemulihan atau pulih asal setelah melakukan aktivitas latihan baik fisik maupun psikis (mental) sebagai proses pemulihan yang bersifat multi dimensional, sama pentingnya dengan latihan warming - up (pemanasan) karena pulih asal merupakan aktivitas fisik sistematis yang bertujuan untuk meningkatkan fungsi fisiologis dan psikologis dalam mencapai tugas-tugas latihan. Pulih asal (recovery) diperlukan agar tubuh dapat menghilangkan produksi asam laktat yang berlebihan akibat latihan dengan intensitas tinggi. Kadar asam laktat yang tinggi dalam darah dapat mengakibatkan kelelahan, diiringi meningkatnya denyut nadi. Dengan demikian diperlukan pemulihan baik secara aktif (fisik) maupun pemulihan pasif (psikis). Selanjutnya pemulihan aktif merupakan gerakan aktif (fisik) joging dengan intensitas lebih kurang 50\% dari kecepatan maksimal.Pemulihan pasif, dengan massage.

Penelitian ini mengkaji metode latihan dengan pemulihan dalam sepak bola yaitu, metode latihan pemulihan aktif dan metode latihan pemuluhan pasif terhadap peningkatan VO2 Max pemain sepak bola yang mengambil mata kuliah sepak bola pada program studi penjaskes Universitas Lampung. Sebagai bahan pertimbangan, perlu diteliti mana yang lebih baik serta lebih cepat dalam menghilangkan asam laktat tubuh antara metode latihan pemulihan aktif dengan metode latihan pemulihan pasif terhadap peningkatan VO2 Max. Dengan demikian akan didapat data empiris tentang hasil pelatihan, dan efektivitas metode latihan dalam peningkatan VO2 Max.

Menurut Richard dan Edward (1992) berpendapat VO2 Max adalah jumlah maksimal oksigen yang diangkut dan digunakan oleh kerja otot-otot. VO2 max secara luas diakui sebagai representasi dari keterbatasan fungsionl dari sistem kardiovaskular serta ukuran kebugaran aerobik (Astorino et al. 2000). Daya tahan kardiovaskular berarti kemampuan jantung, sistem pembuluh darah dan sistem pernapasan termasuk oksigen ke otot secara terus-menerus saat melakukan aktivitas (Berahim dan Kassim 2016). Dengan demikian dapat disimpulkan bahwa 
VO2 Max bagi olahragawan adalah kemampuan tubuh dalam mengangkut dan menggunakan oksigen dalam berolahraga. VO2 Max adalah ukuran maksimal volume oksigen yang digunakan untuk sesorang, hal ini diukur dalam milimeter per kilogram dari berat badan per menit (ml / kg / menit) (Husen 2013). Salah satu cara untuk memeriksa kebugaran seseorang dalam melakukan aktifitas adalah dengan mengukur VO2 max. VO2 max adalah jumlah maksimum oksigen dalam milimeter, yang dapat digunakan dalam 1 menit / kilo gram berat badan (Magsalmina 2007).

Berdasarkan uraian di atas dapat disimpulkan bahwa pemain sepak bola membutuhkan VO2 Max yang baik. Sedangkan VO2 Max adalah jumlah maksimal oksigen yang diangkut dan digunakan oleh kerja otot-otot selama berolahraga. Latihan menurut kamus besar Bahasa Indonesia berasal dari kata dasar latih dan dapat diartikan belajar unuk memperoleh suatu kemampuan atau kecakapan (P dan K 1989). Belajar dan membiasakan diri agar mampu melakukan sesuatu untuk menjadi bisa melakukan sesuatu atau untuk menjadi biasa melakukan sesuatu disebut latihan. Dan latihan itu sendiri akan meningkatkan tubuh dalam melakukan keinginan kerja atau kebutuhan kerja.

Latihan harus dilakukan secara sistematis dan terencana .seperti yang telah dikatakan : Proses yang sistematis dari pada berlatih atau bekerja secara berulangulang dengan kian menambah jumlah beban atau pekerjaannya (Harsono 1986). Menurut Tudor O Bompa (1991), prinsip-prinsip yang harus diperhatikan dalam pembuatan program latihan adalah sebagai berikut: 1). Prinsip aktif dan seksama dalam partisipasi latihan, 2).Pengembangan secara multilateral, 3). Prinsip latihan teratur, 4). Prinsip kontinyuitas, 5). Prinsip penambahan beban latihan (over load), 6). Prinsip progresif, 7). Prinsip titik balik, 8). Prinsip tekanan, 9). Prinsip variasi dalam latihan, 10). Prinsip pemulihan, 11). Prinsip pentahapan dan periodisasi, 12). Prinsip spesifik, 13). Prinsip individualisasi, dan 14). Prinsip spesialisasi. Jadi latihan itu harus berdasarkan prinsip-prinsip tersebut yaitu aktif dan sungguhsungguh dalam latihan, pengembangan secara menyeluruh, spesialisasi, individualisasi, variasi, model proses latihan, dan peningkatan beban secara progresif. 
Menurut Junusul (1989), latihan kontinyu apabila latihan dilakukan tanpa berhenti selama sesi latihan dengan demikian dapat dijelaskan bahwa latihan kontinyu adalah latihan yang dilakukan secara terus menerus sampai akhir selesai sesi latihan tanpa berhenti atau istirahat. Dalam metode latihan ini terdapat beberapa bentuk latihan kontinyu yang terdiri atas bentuk latihan kontinyu paddling, medium paced kontinyu paddling dan fast kontinyu paddling. Interval training diciptakan oleh Woldemar gersclear, sistem latihan interval training adalah merupakan sistem latihan yang sangat penting.Interval training adalah salah satu bagian dari training program yang sangat penting dalam jadwal latihan yang modern. Interval training adalah latihan kondisi fisik yang sangat dianjurkan oleh semua pelatih terkenal oleh karena memang hasilnya sangat positif dalam perkembangan endurance dan stamina atlet. Interval merupakan sistem latihan yang tidak akan ketinggalan jaman, karena akan selalu mengikuti perkembangan. Salah satu dari sistem latihan yang berdasarkan perkembangan research ilmiah untuk mempersiapkan olahraga yang muncul pada abad modern ini adalah interval training (Woeryanto 1966).

Metode adalah suatu cara yang sistematis yang digunakan untuk mencapai tujuan sehingga dipakai sebagai satu cara yang berfungsi sebagai alat untuk mencapai tujuan. Latihan atau training adalah suatu proses berlatih yang sistematis dan dilakukan secara barulang - ulang, kian hari jumlah latihan kian bertambah (Harsono 1993).

\section{METODE}

Metode yang digunakan dalam penelitian ini adalah metode eksperimen. Eksperimen adalah kegiatan yang direncanakan dan dilaksanakan oleh peneliti untuk mengumpulkan data yang ada hubungannya dengan hipotesis. Peneliti dengan sengaja dan secara sistematis memasukkan perlakuan secara alamiah dan kemudian mengamati akibat dari perlakuan tersebut dalam bentuk yang sederhana.

Rancangan penelitian ini menggunakan rancangan Faktorial 2 x 2 . Rancangan Faktorial adalah unit-unit eksperimen dikelompokkan ke dalam sel 
sedemikian rupa secara acak, sehingga unit-unit eksperimen dalam setiap sel relatif bersifat homogen. Sampel dikenakan secara acak kepada unit-unit eksperimen dalam setiap sel.

Tabel 1 Matrik Pengelompokan Sampel Eksperimen

\begin{tabular}{|l|l|l|}
\hline Pemulihan & Denyut Nadi Tinggi & Denyut Nadi Rendah \\
\hline Aktif & 10 & 10 \\
\hline Pasif & 10 & 10 \\
\hline
\end{tabular}

\section{HASIL DAN PEMBAHASAN}

Hasil penelitian yang disajikan memuat tentang deskripsi data, pengujian persyaratan analisis dan pengujian hipotesis dengan penjelasan sebagai berikut.

Penelitian ekperimen ini melibatkan tiga jenis variabel, yaitu variabel terikat, variabel bebas dan variabel atribut. Variabel terikat adalah VO2 Max diperoleh mahasiswa setelah mengalami proses latihan. Metode latihan untuk meningkatkan VO2 max adalah metode latihan denyut nadi tinggi dan metode latihan denyut nadi rendah. Sedangkan variabel atribut adalah Metode Pemulihan yang terdiri dari kategori Metode Pemulihan Aktif dan Metode Pemulihan Pasif.

Data hasil VO2 max yang dipergunakan dalam analisis berupa data dari hasil tes dengan menggunakan instrumen tes VO2 Cooper test yang teruji validitasnya. Penilaian dilakukan terhadap tes VO2 Max yang menggunakan metode latihan denyut nadi tinggi maupun yang menggunakan metode latihan denyut nadi rendah. Sebelum melakukan tes, terlebih dahulu sampel (mahasiswa) diberi kesempatan untuk melakukan pemanasan. Pelaksanaan tes hanya diberi satu kali kesempatan berlari dalam lintasan 400m dengan waktu 12 menit dan langsung dicatat. Hasil Cooper Test tersebut kemudian dikonversi dengan rumus Cooper Test untuk mendapatkan skor VO2 Max. Dari hasil Vo2 max tersebut diperoleh data tes akhir dari perlakuan, sehingga merupakan hasil dari metode latihan denyut nadi tinggi dan metode latihan denyut nadi rendah. 
Rangkuman harga-harga $\mathrm{n}, \bar{X}$, dan SD untuk setiap perlakukan diperlihatkan pada tabel 2 berikut ini.

Tabel 2 Rangkuman Hasil Perhitungan nilai $\bar{X}$ dan SD data hasil penelitian

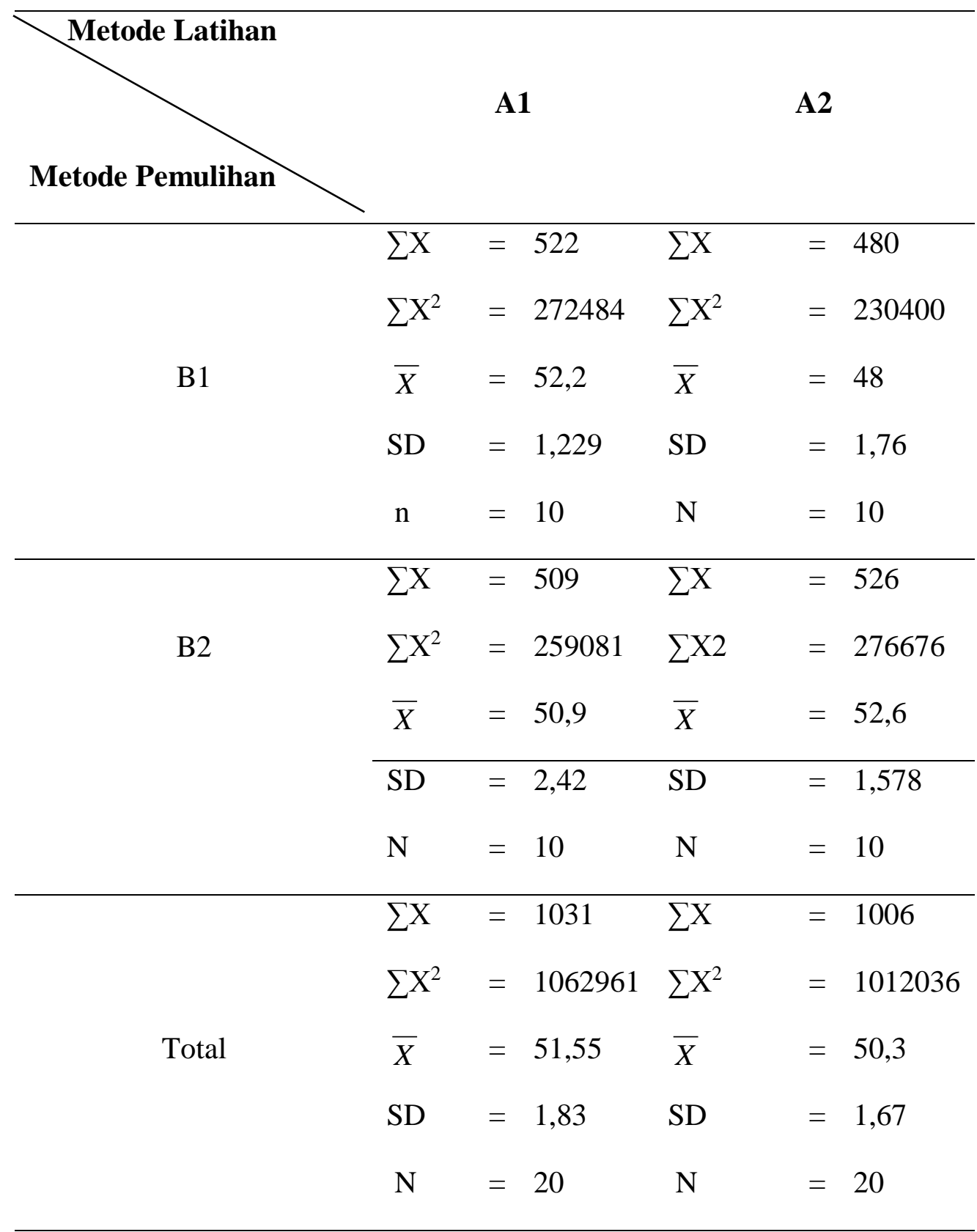


Hasil Vo2 max Kelompok yang Dilatih dengan Metode Latihan Denyut Nadi Tinggi Secara Keseluruhan

Data hasil Vo2 max pada kelompok yang dilatih dengan metode latihan denyut nadi tinggi secara keseluruhan, diperoleh rentang antara 48 sampai 57, di dapatkan $\bar{X}=51,55, \mathrm{SD}=1,83$ dan distribusi frekuensi sebagaimana tampak dalam tabel 3 di bawah ini.

Tabel 3 Distribusi frekuensi skor hasil VO2 max pada kelompok metode latihan denyut nadi tinggi secara keseluruhan

\begin{tabular}{|c|c|c|c|c|}
\hline \multirow{2}{*}{$\begin{array}{l}\text { No } \\
1\end{array}$} & \multicolumn{2}{|c|}{ Kelas Interval } & \multirow{2}{*}{$\begin{array}{l}\text { Frek. Absolut } \\
4\end{array}$} & \multirow{2}{*}{$\begin{array}{l}\text { Frek. Relatif (\%) } \\
20\end{array}$} \\
\hline & 48 & $\begin{array}{ll}-49 \\
\end{array}$ & & \\
\hline 2 & 50 & -51 & 5 & 25 \\
\hline 3 & 52 & -53 & 9 & 45 \\
\hline 4 & 54 & -55 & 1 & 5 \\
\hline 5 & 56 & -57 & 1 & 5 \\
\hline Jun & & & 20 & 100 \\
\hline
\end{tabular}

Berdasarkan tabel 3 didapat 10\% (2 orang) memperoleh skor hasil VO2 max di atas rata-rata, $45 \%$ (9 orang) pada rata-rata dan $45 \%$ ( 9 orang) di bawah rata-rata.

\section{Hasil Vo2 max Kelompok yang Dilatih dengan Metode Latihan Denyut Nadi Rendah Secara Keseluruhan}

Data hasil VO2 max pada kelompok yang dilatih dengan metode latihan denyut nadi rendah secara keseluruhan, diperoleh rentang antara 46 sampai 55, di dapatkan $\bar{X}=50,3, \mathrm{SD}=1,67$ dan distribusi frekuensi sebagaimana tampak dalam tabel 4. 
Tabel 4 Distribusi frekuensi skor hasil Vo2 max pada kelompok metode latihan denyut nadi rendah secara keseluruhan

\begin{tabular}{cccccc}
\hline No & \multicolumn{2}{c}{ Kelas Interval } & Frek. Absolut & Frek. Relatif (\%) \\
\hline 1 & 46 & - & 47 & 4 & 20 \\
\hline 2 & 48 & - & 49 & 4 & 20 \\
\hline 3 & 50 & - & 51 & 4 & 20 \\
\hline 4 & 52 & - & 53 & 4 & 20 \\
\hline 5 & 54 & - & 55 & 4 & $\mathbf{1 0 0}$ \\
\hline & Jumlah & $\mathbf{2 0}$ & 20 \\
\hline
\end{tabular}

Berdasarkan tabel 4 didapat 40 (8 orang) memperoleh skor hasil Vo2 max di atas rata-rata, $20 \%$ (4 orang) pada rata-rata dan $40 \%$ (8 orang) di bawah ratarata.

Hasil VO2 max Kelompok Pemulihan Aktif yang Dilatih dengan Metode Latihan Denyut Nadi Tinggi (A1B1)

Data hasil VO2 max pada kelompok pemulihan aktif yang dilatih dengan metode latihan denyut nadi tinggi diperoleh rentang antara 50 sampai 54 di dapatkan $\bar{X}=52,2$ SD $=1,299$ dan distribusi frekuensi sebagaimana terlihat dalam tabel 5 di bawah ini.

Tabel 5 Distribusi frekuensi skor hasil Vo2 max pada kelompok pemulihan aktif yang dilatih dengan metode latihan denyut nadi tinggi

\begin{tabular}{cccccc}
\hline No & \multicolumn{2}{l}{ Kelas Interval } & Frek. Absolut & Frek. Relatif (\%) \\
\hline 1 & 50 & - & 51 & 3 & 30 \\
\hline 2 & 51 & - & 52 & 2 & 20 \\
\hline 3 & 52 & - & 53 & 4 & 40 \\
\hline 4 & 53 & - & 54 & 1 & 10 \\
\hline & Jumlah & $\mathbf{1 0}$ & $\mathbf{1 0 0}$ \\
\hline
\end{tabular}


Berdasarkan tabel 5 di atas, didapat 10\% (1 orang) memperoleh skor hasil Vo2 max di atas rata-rata, 40\% (4 orang) pada rata-rata dan 50\% (5 orang) di bawah rata-rata.

Hasil Vo2 max Kelompok Pemulihan Pasif yang Dilatih dengan Metode Latihan Denyut Nadi Tinggi (A1B2)

Data hasil Vo2 max pada kelompok pemulihan pasif yang dilatih dengan metode latihan denyut nadi tinggi, diperoleh rentang antara 48 sampai 55, di dapatkan $\bar{X}=50,9, \mathrm{SD}=2,42$ dan distribusi frekuensi sebagaimana tampak dalam tabel 6 .

Tabel 6 Distribusi frekuensi skor hasil Vo2 max pada kelompok pemulihan pasif yang dilatih dengan metode latihan denyut nadi tinggi

\begin{tabular}{cccccc}
\hline No & \multicolumn{2}{l}{ Kelas Interval } & Frek. Absolut & Frek. Relatif (\%) \\
\hline 1 & 48 & - & 49 & 4 & 40 \\
\hline 2 & 50 & - & 51 & 2 & 20 \\
\hline 3 & 52 & - & 53 & 3 & 30 \\
\hline 4 & 54 & - & 55 & 1 & 10 \\
\hline \multicolumn{7}{l}{ Jumlah } & $\mathbf{1 0}$ & $\mathbf{1 0 0}$ \\
\hline
\end{tabular}

Berdasarkan tabel 6 didapat 40\% (4 orang) memperoleh skor hasil Vo2 max di atas rata-rata, 20\% (2 orang) pada rata-rata dan $40 \%$ (4 orang) di bawah rata-rata.

Hasil Vo2 max Kelompok Pemulihan Aktif yang Dilatih dengan Metode Latihan Denyut Nadi Rendah (A2B1)

Data hasil VO2 max kelompok pemulihan aktif dengan metode latihan denyut nadi rendah, diperoleh rentang antara 46 sampai 53, didapatkan $\bar{X}=48$ $\mathrm{SD}=1,76$ dan distribusi frekuensi sebagaimana tampak dalam tabel 7 di bawah ini. 
Tabel 7 Distribusi frekuensi skor hasil Vo2 max kelompok pemulihan aktif dengan metode latihan denyut nadi rendah

\begin{tabular}{cccccc}
\hline No & \multicolumn{2}{c}{ Kelas Interval } & Frek. Absolut & Frek. Relatif (\%) \\
\hline 1 & 46 & - & 47 & 4 & 40 \\
\hline 2 & 48 & - & 49 & 4 & 40 \\
\hline 3 & 50 & - & 51 & 2 & 20 \\
\hline 4 & 52 & - & 53 & - & - \\
\hline & Jumlah & & $\mathbf{1 0}$ & $\mathbf{1 0 0}$ \\
\hline
\end{tabular}

Berdasarkan tabel 7 di atas didapat 20\% (2 orang) memperoleh skor hasil Vo2 max di atas rata-rata, 40\% (4 orang) pada rata-rata dan 40\% (4 orang) di bawah rata-rata.

Hasil Vo2 max Kelompok Pemulihan Pasif yang Dilatih dengan Metode Latihan Denyut Nadi Rendah (A2B2)

Data hasil VO2 max kelompok pemulihan pasif dengan metode latihan interval, diperoleh rentang antara 50 sampai 54, di dapatkan $\bar{X}=52,6, \mathrm{SD}=$ 1,578 dan distribusi frekuensi sebagaimana tampak dalam tabel 8 .

Tabel 8 Distribusi frekuensi skor hasil hasil Vo2 max kelompok pemulihan pasif dengan metode latihan denyut nadi rendah

\begin{tabular}{cccccc}
\hline No & \multicolumn{2}{c}{ Kelas Interval } & Frek. Absolut & Frek. Relatif (\%) \\
\hline 1 & 50 & - & 51 & 2 & 20 \\
\hline 2 & 51 & - & 52 & 2 & 20 \\
\hline 3 & 52 & - & 53 & 2 & 40 \\
\hline 4 & 53 & - & 54 & 4 & $\mathbf{1 0 0}$ \\
\hline
\end{tabular}


Berdasarkan tabel, didapat 40\% (4 orang) memperoleh skor hasil Vo2 max di atas rata-rata, $20 \%$ (2 orang) pada rata-rata dan $40 \%$ (4 orang) di bawah rata-rata.

\section{Interaksi Antara Metode Latihan dengan Metode Pemulihan terhadap VO2} $\operatorname{Max}$

VO2 Max kelompok mahasiswa setelah dilatih dengan menggunakan metode latihan denyut nadi tinggi dan latihan dengan denyut nadi rendah, baik mahasiswa yang menggunakan metode pemulihan aktif maupun pasif. Data yang diperoleh dapat di lihat pada tabel 9 yang menggambarkan harga rata-ratanya.

Tabel 9 Rata-rata VO2 Max keempat kelompok

\begin{tabular}{lllll}
\hline Metode Latihan & $\begin{array}{l}\text { Denyut } \\
\text { Tinggi (A1) }\end{array}$ & $\begin{array}{l}\text { Nadi } \\
\bar{X}\end{array}$ & $\begin{array}{l}\text { Denyut } \\
\text { Rendah (A2) }\end{array}$ & Nadi \\
\hline Aktif (B1) & $\bar{X}$ & 52,2 & $\frac{X}{X}=48$ \\
\hline Pasif (B2) & $=50,9$ & $=52,6$ \\
\hline
\end{tabular}

Berdasarkan dari data pada tabel di atas, dapat diambil kesimpulan bahwa hasil VO2 Max mahasiswa kelompok pemulihan aktif yang dilatih dengan metode latihan denyut nadi tinggi ( $\bar{X}=52,2$ ) lebih tinggi jika dibandingkan dengan kelompok mahasiswa yang dilatih dengan metode latihan denyut nadi rendah $(\bar{X}=48)$. Sedangkan sebaliknya hasil VO2 Max mahasiswa yang kelompok pemulihan pasif yang dilatih dengan metode latihan denyut nadi tinggi ( $\bar{X}=$ 50,9) lebih rendah jika dibandingkan dengan kelompok mahasiswa yang dilatih dengan metode latihan denyut rendah rendah $(\bar{X}=52,6)$. Dengan demikian dapat diduga bahwa terdapat interaksi antara metode latihan dengan metode pemulihan dalam peningkatan VO2 Max.

\section{Pembahasan}


Secara keseluruhan metode latihan denyut nadi tinggi lebih baik dari pada latihan denyut nadi rendah.

Metode latihan merupakan faktor yang sangat penting karena keberhasilan mencapai tujuan tergantung dari metode yang digunakan. Dalam penelitian ini dieksperimenkan dua macam metode latihan yaitu latihan denyut nadi tinggi dan metode latihan denyut nadi rendah. Kedua metode ini masing-masing memiliki kelebihan dan kelemahan namun mempunyai tujuan yang sama yaitu mengoptimalkan kemampuan pemain dalam menemukan makna hakiki latihan. Dengan demikian dapat disimpulkan bahwa metode latihan denyut nadi tinggi lebih baik dari pada metode latihan denyut nadi rendah.

Pemain yang memakai metode pemulihan aktif metode latihan denyut nadi tinggi lebih baik dari pada metode latihan denyut nadi rendah.

Metode latihan pemulihan aktif dan metode latihan pemulihan pasif memiliki karakteristik pelaksanaan yang berbeda. Metode latihan pemulihan merupakan gerakan aktif dengan joging dengan intensitas kurang lebih 50\% setelah melakukan gerakan maksimal. Hal ini untuk memulihkan denyut nadi yang tinggi setelah melakukan aktivitas joging dengan aktif yang berupa gerak terus menerus dengan kecepatan rendah. Selanjutnya metode pemulihan pasif hanya relaksasi di tempat (massage). Dengan demikian dapat disimpulkan bahwa pemain yang melakukan metode latihan denyut nadi tinggi lebih baik menggunakan pemulihan aktif dibandingkan metode latihan denyut nadi rendah.

Bagi pemain yang memakai metode pemulihan pasif latihan denyut nadi rendah lebih baik dari latihan denyut nadi tinggi.

Dalam pemulihan pasif waktu istirahat lebih banyak dibandingkan dengan metode pemulihan aktif, setelah melakukan penampilan kinerja latihan, maka denyut nadi akan tetap tinggi sehingga kecepatan menurun. Denyut nadi akan tetap tinggi disaat intensitas sub maksimal, pada metode pemulihan pasif akan masuk oksigen pada saat istirahat cara bernapas (proses oksidasi) dan tidak cepat atau tidak langsung diedarkan ke seluruh tubuh sehingga cepat dalam menghilangkan asam laktat pada tubuh (proses neurpsikologis). Dengan demikian dapat disimpulkan bahwa pemain yang melakukan metode latihan denyut nadi 
rendah lebih baik menggunakan pemulihan pasif dibandingkan metode latihan denyut nadi tinggi.

\section{Terdapat interaksi antara metode latihan dan metode pemulihan.}

Metode latihan denyut nadi tinggi dan metode latihan denyut nadi rendah mempunyai tujuan yang sama walaupun berbeda dalam karakteristik pelaksanaannya. Metode latihan denyut nadi tinggi dan metode latihan denyut nadi rendah mempengaruhi tinggi atau rendahnya pemulihan yang pada akhirnya akan berpengaruh pada peningkatan VO2 Max, penimbunan asam laktat dan tidak cepat lelah. Dengan demikian dapat disimpulkan terdapat interaksi antara metode latihan dengan metode pemulihan terhadap peningkatan VO2 Max.

\section{SIMPULAN}

Berdasarkan data hasil penelitian yang telah dilaksanakan, dapat disimpulkan bahwa secara keseluruhan metode latihan denyut nadi tinggi lebih baik dari pada latihan denyut nadi rendah, bagi mahasiswa yang melakukan latihan pemulihan aktif metode latihan denyut nadi tinggi lebih baik dari pada metode latihan denyut nadi rendah, bagi mahasiswa yang melakukan pemulihan pasif metode latihan denyut nadi rendah lebih baik dari pada metode latihan denyut nadi tinggi, serta terdapat interaksi antara metode latihan dan metode pemulihan terhadap peningkatan VO2 Max.

\section{DAFTAR PUSTAKA}

Astorino TA, Robergs RA, Ghiasvand F, Marks D, Burns S. 2000. Incidence of the Oxygen Plateau at VO2 Max During Exercise Testing to Volitional Fatigue Sports. Journal of exercise and applied human physiology. Vol 3(4), hal. 1-12.

Berahim M, Kassim M. 2016. Analysis of Physical Fitness Test on Junior Football Players. Jurnla of Scientific Research and Development. Vol 3(4), hal. 15-23.

Browers WR and Edward LW. 1992. Sport Pysiology. Lowa. Brown Publisher Hairy J. 1989. Fisiologi Olahraga. Jakarta (ID): Depdikbud.

Harsono. 1993. Prinsip - prinsip Pelatihan. Jakarta (ID): Koni Pusat Pendidikan dan Penataran.

Harsono. 1986. Ilmu Coaching. Jakarta(ID): PIO KONI Pusat. 
Husen. 2013. Pengaruh Latihan Small Slide Game Terhadap Peningkatan VO2 Max. Jurnal Ilmiah.

Magsalmina M. 2007. Pengaruh Latihan Aerobik Terhadap Perubahan VO2 Max. Jurnal Ilmiah.

O Bompa Tudor. 1991. Teori dan Metodologi Latihan. Jakarta (ID): FPOK IKIP Jakarta.

P dan K .1989. Kamus Besar Bahasa Indonesia. Jakarta (ID): Balai Pustaka.

Woeryanto. 1966. Interval Training. Jakarta (ID): Pusat Kebudayaan Cekoslowakia. 